\title{
Beliefs About Gender Differences in Methods and Causes of Suicide
}

Francis T. McAndrew and Andrew J. Garrison

Query Sheet

Q1 Au: Please provide keywords. 


\title{
Beliefs About Gender Differences in Methods and Causes of Suicide
}

\author{
Francis T. McAndrew and Andrew J. Garrison
}

Forty undergraduate students (20 Males, 20 females) made judgments about the relationship between an individual's gender and the method of suicide most likely to be chosen by that individual. The perceived relationship between different precipitating events for suicide and the method of suicide were also examined, as were the participants' judgments about the moral justifiability of suicide in response to different traumatic situations. The results indicated clear and consistent beliefs about the relationship between the gender of the potential suicide victim, the method of suicide likely to be chosen, and whether or not the cause of the suicide was judged harshly or sympathetically. Understanding how the gender of an at-risk individual interacts with an observer's beliefs and moral perspective should help us predict when suicide threats will be taken seriously and what form of intervention will take place.

In the United States in the year 2000, suicide was the third leading cause of death among 10 to 19 year-olds (Anderson, 2002). Since 1955, the suicide rate for American young 20 people has climbed steadily, especially for males (Cantor, 2000; Hendin, 1995; Kessler \& McRae, 1983). Studies have found that almost half of college-aged individuals reported some degree of thinking

25 about suicide (suicidal ideation) during the previous year (Rudd, 1989), and more than a third had been told of such thoughts by a peer (Mishara, 1982). Given the magnitude of the problem and the fact that it

30 appears to be getting worse rather than improving, any information that would facilitate the speedy identification of at-risk individuals and enhance the effectiveness of intervention programs will be highly 35 valued.

The gender of suicidal individuals is intimately bound up with many different aspects of the suicide situation. There has been a long-standing belief that men are more likely to kill themselves as a result 40 of failure in some arena of achievement and that women are more likely to die as a result of romantic relationships that have gone bad (Barnes, 1985; Hawton, 2000; Jack, 1992; Wilson, 1981). However, actual 45 studies of the concerns of suicidal individuals as revealed in suicide notes or other forms of communication generally fail to find consistent differences between the factors precipitating suicide for men and 50 for women (Canetto, 1992-1993, 1997a; Hjelmeland, Knizek, \& Nordvik, 2002). In fact, both men and women report mental illness, loneliness, and rejection by a lover as the primary triggers for suicide 55 (Canetto \& Lester, 2002; Hjelmeland, Knizek \& Nordvik, 2002). Among adolescents, many suicide attempts are clearly a strategic response to family conflict and an effort to 
60 leverage greater sympathy and investment from parents (Andrews, 2006; Spirito, Valeri, Boergers et al., 2003; Wagner, 1997; Wagner, Aiken, Mullaley et al., 2000). The failure to understand that the

65 most likely causes of suicide may be the same for males and females may lead observers to underestimate the true risk of suicide if the concerns expressed by the suicidal person do not match the

70 expectations held by the observer about the typical suicide triggers for that individual's gender.

Much has also been made about the fact that, at least in North America, young

75 males die by suicide far more often than do young females, even though females report thinking about it, talking about it, and actually attempting it more often than males (Anderson, 2002; Garrison,

80 McKeown, Valois et al., 1993; Gmitrowicz, Szymczak, Kropiwnicki et al., 2003; Lewinsohn, Rohde, \& Seeley, 1996). While some researchers (e.g., Gould, Greenberg, Velting et al., 2003) have proposed that a

85 variety of psychopathological and sex-role differences may account for this pattern, it is more easily explained if it is recognized that suicide attempts are a different class of behaviors from actual suicides (Kessler

90 \& McRae, 1983). Although some suicides are undoubtedly the result of feigned attempts gone wrong, just as some "attempts" are the botched result of genuinely suicidal plans, there is evidence that

95 the intentions of individuals in the two situations may be quite different. Correctly identifying the intentions of individuals ruminating about suicide is essential for assessing the risk of suicide and the appro-

100 priate method of intervention (Schneidman, 1985). Actual suicide is an attempt to end life, but attempted suicide may very well be an effort to improve one's life (Pokorny, 1965). In short, suicide attempts are a form

105 of communication. Although males and females do not seem to be communicating different things with suicide attempts, women are significantly more likely than men to initiate a suicide attempt without actually intending to die, and this may 110 account for the male-female disparity in suicide attempts and completions (Hjelmeland, Knizek \& Nordvik, 2002). Consistent with this view, nonfatal suicide attempts have traditionally been thought of as "feminine" 115 behaviors by young adults in North America (Canetto, 1997b), and women are usually judged more harshly than men for committing suicide (Canetto, 1997b; Deluty, 1988-1989; Linehan, 1973). Curiously, 120 although men are typically more accepting of an individual's right to commit suicide than are women, men also tend to judge suicidal individuals more harshly than do women (Deluty, 1988-1989; Marks, 125 1988-1989; Stillion \& Stillion, 1998-1999; White \& Stillion, 1988). Among young adults, physical illness is judged to be one of the most legitimate reasons for committing suicide (Dahlen \& Canetto, 2002).

Although the factors that lead to suicide may not be that different for males and females, there are clear gender differences in the preferred methods for suicide. Over time, males have consistently chosen 135 more active and lethal suicide techniques such as firearms, hanging, and jumping from high places. Females, on the other hand, have traditionally favored more passive and less reliable methods such as drug 140 overdoses and drowning (Chotai, Renberg, \& Jacobsson, 2002; Glasser-Frei, 2003; Pirkola, Isometsa \& Lohnqvist, 2003). Males are more likely than females to attempt suicide under the influence of alco- 145 hol (Pirkola, Isometsa \& Lohnqvist, 2003). The U.S. Center for Disease Control and Prevention reported in 2004 that hanging and other forms of suffocation are the chief means of suicide for young teens 150 (ages 10-14), and that shooting oneself is the most frequent method of choice for older teens (15-19).

It is the goal of the present study to examine the perceptions of college students 155 
about the relationships among a potential suicide victim's gender, the moral acceptability of various motivators for suicide, and whether or not there is a perceived relation-

160 ship between the method chosen for a suicide and the type of precipitating event. These are important questions, because peers are usually the first to detect disturbing behavior changes and they are also the people most

165 likely to be confided in by suicidal friends. Hence, understanding how potential suicide situations are perceived by these individuals could ultimately lead to earlier identification of young adults who are at-risk (Mueller \&

170 Waas, 2002). Furthermore, understanding how the gender of an at-risk individual interacts with an observer's beliefs about methods and causes of suicide should help us predict the circumstances in which suicide threats will

175 be taken seriously, when empathy will occur, and how the observers will communicate with potential victims (Limbacher \& Domino, 1985-1986; Mueller \& Waas, 2002; White \& Stillion, 1988).

180

METHOD

Participants

Forty undergraduate students (20 males, 20 females) from a small liberal arts college in the American Midwest participated in this study. All participants were volunteers 185 recruited from undergraduate classes in which they could receive course credit for participation. Most of the participants were between the ages of 18-22, and most of them were Caucasians. There were some American minority students in the sample as well as a few international students, but because this demographic information was not requested, their exact numbers are unknown. No effort was made to determine if any of the participants had any current or past experience with suicidal behaviors or ideation.

\section{Materials \& Procedure}

Participants were told that they would be fill- 200 ing out a questionnaire asking for their beliefs about suicide. Participants filled out the questionnaire in a classroom setting; all students completed the questionnaire in 25 minutes or less. Each participant recorded his or her 205 sex on the questionnaire and read a set of written instructions. In the first section of the document, the participant read ten different suicide scenarios generated specifically for this experiment (Table 1). Each scenario 210 was a statement describing a suicide by a college student with an unambiguously male or female first name. In one version of the questionnaire, the odd numbered scenarios described the suicide of a male and the even 215

\section{TABLE 1. The Ten Suicide Scenarios*}

Marcus committed suicide by purposely taking a lethal amount of poison.

Sarah committed suicide by purposely running her vehicle into a tree.

Richard committed suicide by slicing his wrists.

Bridget committed suicide by throwing herself into a deep, fast moving river.

Logan committed suicide by hanging himself.

Miranda committed suicide by shooting herself with a gun.

Ryan, an experienced drug user, committed suicide by knowingly taking a lethal amount of an illegal drug.

Karen committed suicide by throwing herself in front of a moving train

Nick committed suicide by knowingly taking a lethal amount of an over the counter drug.

Britney committed suicide by jumping from a high altitude bridge onto solid ground.

\footnotetext{
*Each scenario was presented an equal number of times with a male or female protagonist.
} 
numbered questions described the suicide of a female. This pattern was reversed in the alternate version of the questionnaire so that an equal number of participants would react 220 to each suicide scenario for male and female victims. Thus, 10 males and 10 females responded to each version of the questionnaire. Following each statement/scenario, there was a list of nine possible reasons

225 for the suicide described in the scenario (Table 2). The participants rated each of the nine reasons on a 1 (very likely) to 5 (very unlikely) scale as to how likely the event would be to result in a suicide by the method

230 described in the statement. For this part of the study, the independent variables were the sex of the participant, the sex of the suicide victim, and the method of suicide. The dependent variable was the likelihood rating

235 given to each of the suicide causes for each question.

For the second part of the questionnaire, we compiled a list of ten possible methods of suicide. The participants had to indicate via

240 forced-choice whether they believed that the method of suicide was more likely to be used by a male or by a female when committing suicide. The ten methods of suicide are also listed in Table 2. In this portion of

245 the tudy, the independent variables were the method of suicide and the sex of the participant, and the dependent variable was the frequency with which each suicide technique was chosen as a typically male versus female method of suicide.

The third and final part of the questionnaire presented participants with a list of 15 possible reasons that a person might commit suicide. These reasons were generated specifically for this experiment. Their 255 task was to indicate on a 1 (completely unjustifiable) to 10 (completely justifiable) scale how morally justifiable a suicide prompted by each event would be. This was done twice, once for a male victim 260 and once for a female victim. In this portion of the study, the independent variables were the sex of the suicide victim and the nature of the precipitating event. The dependent variable was the rating of moral 265 justifiability. (The list of 15 suicide causes that were judged for moral justifiability can be seen in Table 4 alongside the presentation of results.)

RESULTS 270

Perceived Gender Differences in Methods of Suicide

We will first report the analyses for the second portion of the questionnaire in

TABLE 2.

\begin{tabular}{ll}
$\begin{array}{l}\text { The Nine Possible Reasons for } \\
\text { Suicide Evaluated by the Participants }\end{array}$ & $\begin{array}{l}\text { Ten Methods of Suicide Judged as Most } \\
\text { Likely to be Chosen by a Male or Female }\end{array}$ \\
\hline Money troubles & Use of poison \\
Family troubles & Hanging \\
Romantic troubles & Jumping from bridge \\
Academic troubles & Overdose (illegal drugs) \\
Loneliness & Overdose (legal drugs) \\
Physical illness & Jumping in front of moving vehicles \\
Depression & Crashing car purposely \\
Hopelessness about the future & Slitting wrists \\
Feelings of failure & Shooting one's self \\
& Drowning \\
\hline
\end{tabular}


TABLE 3. Results of Chi-Square Analyses

\begin{tabular}{llc}
\hline Method of Suicide & Chi-Square (df) & Significance Level \\
\hline Shooting one's self & $\mathrm{X}^{2}(1)=40.00$ & $\mathrm{p}<.0001$ \\
Hanging & $\mathrm{X}^{2}(1)=25.60$ & $\mathrm{p}<.0001$ \\
Overdose (illegal drugs) & $\mathrm{X}^{2}(1)=19.60$ & $\mathrm{p}<.0001$ \\
Jumping in front of moving vehicle & $\mathrm{X}^{2}(1)=16.90$ & $\mathrm{p}<.001$ \\
Jumping from bridge & $\mathrm{X}^{2}(1)=10.00$ & $\mathrm{p}<.01$ \\
Slitting wrists & $\mathrm{X}^{2}(1)=25.60$ & $\mathrm{p}<.0001$ \\
Overdose (legal drugs) & $\mathrm{X}^{2}(1)=16.90$ & $\mathrm{p}<.001$ \\
Use of poison & $\mathrm{X}^{2}(1)=10.00$ & $\mathrm{p}<.01$ \\
Drowning & $\mathrm{X}^{2}(1)=10.00$ & $\mathrm{p}<.01$ \\
Purposely crashing car & $\mathrm{X}^{2}(1)=.40$ & $\mathrm{p}>.05$ \\
\hline
\end{tabular}

TABLE 4. Means and Standard Deviations for Judgments of the Moral Justifiability of Suicide Causes*

\begin{tabular}{lcc}
\hline Suicide Cause & $\begin{array}{c}\text { Males } \\
\text { Mean (SD) }\end{array}$ & $\begin{array}{c}\text { Females } \\
\text { Mean (SD) }\end{array}$ \\
\hline Terminal disease & $6.88(2.79)$ & $6.78(2.72)$ \\
Paralysis & $5.78(3.45)$ & $5.35(2.73)$ \\
$\begin{array}{l}\text { Depression } \\
\text { Parent committing }\end{array}$ & $5.38(2.72)$ & $5.43(2.81)$ \\
$\quad$ suicide & $4.80(2.85)$ & $5.13(2.97)$ \\
Loss of parent & $4.40(2.72)$ & $4.93(2.82)$ \\
$\begin{array}{l}\text { Loneliness } \\
\text { Romantic partner }\end{array}$ & $4.25(2.63)$ & $4.83(2.93)$ \\
$\quad$ dying & $4.83(2.94)$ & $5.00(3.15)$ \\
Hopelessness about & $4.13(2.66)$ & $4.03(2.55)$ \\
$\quad$ future & $2.93(2.21)$ & $3.88(2.95)$ \\
$\begin{array}{l}\text { Obesity } \\
\text { Romantic partner }\end{array}$ & $3.23(2.15)$ & $3.75(2.59)$ \\
$\quad$ leaving & & \\
Financial troubles & $3.50(2.59)$ & $2.93(1.95)$ \\
$\begin{array}{l}\text { Academic problems } \\
\text { Romantic partner }\end{array}$ & $3.38(2.42)$ & $3.45(2.52)$ \\
$\quad 2.80(1.94)$ & $3.38(2.45)$ \\
$\begin{array}{l}\text { Parents divoring } \\
\text { Insecurities about }\end{array}$ & $2.45(1.53)$ & $2.83(2.01)$ \\
$\quad$ attractiveness & $2.00(1.56)$ & $2.73(2.40)$ \\
\hline
\end{tabular}

*All numbers based on responses to a 10 point scale ranging from 1 (completely unjustifiable) to 10 (completely justifiable).

which participants reported whether they 275 thought a specific method of suicide was more likely to be used by a male or a female. Because there were no significant differences in the pattern of responses made by male and female subjects, their 280 responses were combined and analyzed via chi-square tests. The results of all tests that were significant at a .05 level will be reported. However, due to the large number of analyses that were conducted, a Bon- 285 ferroni correction indicated that a more conservative standard of $\alpha=.005$ might be a better guide to use when assessing how much confidence to place in the robustness of a finding. Of the ten meth- 290 ods of suicide, there was only one that was not perceived to be more likely to be chosen by one gender over the other, and that was intentionally crashing a car. The methods that were significantly more likely 295 to be perceived as male suicide methods $(p<.01)$ were shooting one's self, hanging, overdosing on illegal drugs, jumping in front of a moving vehicle, and jumping from a bridge. Methods judged to be sig- 300 nificantly more likely to be used by females $(p<.01)$ included slitting one's wrists, overdosing on legal drugs, poisoning, and drowning. The results of the chi-square analyses can be seen in Table 3 . 
Perceived Moral Justifiability of Suicide

Based Upon the Precipitating Event

The next analysis to be reported involved the moral justifiability for committing suicide for

31015 possible reasons. The means and standard deviations associated with the judgments of moral justifiability for each reason for both male and female suicide victims are presented in Table 4. As can be seen in this table, debil-

315 itating physical and psychological traumas such as terminal illness, paralysis, depression, or the death of a parent or lover were judged to be more morally acceptable excuses for suicide than were concerns about one's

320 appearance, obesity, or the divorce of one's parents. There were, however, slightly different standards applied to male and female victims. Data were analyzed with paired sample $t$ tests in which the participants' ratings of the

325 moral justifiability of each reason for suicide for males was compared to their ratings of moral justifiability for females. As before, we will be reporting all results that reach traditional levels of significance $(\phi<.05)$, but a

330 Bonferroni correction indicated that a more conservative standard of $\alpha=.003$ might be a better guide to use when assessing how much confidence to place in the robustness of a finding. Of the fifteen reasons, there

335 were only six that showed a significant difference between male and female suicide victims. Five of these reasons were judged to be more morally acceptable for females than for males. Specifically, it was judged

340 to be more morally justifiable for females to kill themselves because of loneliness, $t(39)=3.04, p<.01$, loss of a parent, $t(39)=2.72, \quad p<.01, \quad$ insecurities about attractiveness, $\quad t(39)=2.57, \quad p<.02, \quad$ a

345 romantic partner cheating, $t(39)=2.45$, $p<.02$, and a romantic partner leaving, $t(39)=2.41, p<.03$. The only reason for which males were thought to have greater justification for suicide than females was

350 experiencing financial trouble, $t(39)=2.80$, $p<.01$. There were no significant differences $(\phi>.05)$ between male and female suicide victims regarding the moral justifiability of suicide because of terminal disease, parents divorcing, parent suicide, academic 355 problems, hopelessness about the future, or a romantic partner dying.

\section{Perceived Relationships Between Reason for Suicide and Method of Suicide}

The final analyses to be reported looked at 360 the ratings on a five-point scale ("very unlikely" to "very likely") that a particular reason for suicide would lead to a specific method of suicide. These data came from the first portion of the questionnaire in 365 which participants read 10 suicide scenarios for male or female victims and judged how likely each of nine possible reasons for each particular suicide would be. Data were analyzed via a $2 \times 2$ Factorial MANOVA with 370 sex of participant and sex of suicide victim as the independent variables. A separate MANOVA was conducted for each of the 10 suicide scenarios, and the dependent variables were the judgments made for 375 each of the nine precipitating events in each scenario. The Multivariate interaction between participant sex and victim sex was not significant in any of the ten scenarios $(\not>.05)$, indicating that males and 380 females were responding similarly to male and female victims in all of the scenarios. There were, however, three MANOVA main effects. For suicide by throwing one's self into a fast moving river, there was a 385 nearly significant main effect for the participants' sex, $F(9,28)=2.18, \quad p<.055$. Specifically, females (more than males) believed that feelings of failure were likely to lead an individual to throw him- 390 self/herself into a fast moving river, $F(1,36)=8.76, p<.005$. There was also a main effect for the gender of the suicide victim for this method of suicide, $F(9,28)=2.86, p<.02$. Money problems 395 and physical illness were thought to be more likely to lead to suicide by throwing one's self into a fast moving river for 
female victims than for male victims, $F_{\text {Money }}$ 400 Problems $(1,36)=4.28, p<.04, \quad F_{\text {Physical }}$ Illness $(1,36)=4.59, p<.04$. The two other methods of suicide that produced significant MANOVA main effects were gun suicides, $F(9,28)=2.70, p<.02$, and 405 hanging, $F(9,28)=3.63, p<.004$. More specifically, the main effect for gun suicide was a main effect for the gender of the participant in which females more than males believed that loneliness was likely to lead

410 to a suicide by firearms, $F(1,36)=6.63$, $p<.01$. There was no significant main effect for the gender of the victim when it came suicide by gun, $F(9,28)=.28$, n.s. For suicide by hanging, the significant

415 main effect was a main effect for the gender of the victim in which money troubles, $F(1,36)=10.56, p<.003$, and romantic problems, $F(1,36)=5.25, p<.03$, were thought to be more likely to lead to suicide

420 by hanging for male victims than for female victims. For hanging, there was no significant main effect for the gender of the participant, $F(9,28)=.98$, n.s.

\section{DISCUSSION}

425 For the most part, the results of this study fit nicely with the existing body of research on gender and suicide. There was widespread agreement about which suicide methods are stereotypically "male" meth-

430 ods and which are "female" methods, with the male methods (e.g., shooting oneself, hanging, jumping from a bridge or in front of a vehicle) being more predictably lethal than the female methods (drowning, slit435 ting wrists, overdosing/poisoning). As in previous studies (e.g., Dahlen \& Canetto, 2002), serious illness or severe psychological traumas were judged to be the most acceptable reasons for suicide. Consistent

440 with the misperceptions identified by other researchers that people believe that females are more likely to kill themselves over relationship failures and men over achievement-related failures (Barnes, 1985; Hawton, 2000; Jack, 1992; Wilson, 445 1981), our subjects believed that it might be more acceptable for females to commit suicide over relationship and appearance issues and for males to kill themselves because of financial problems. In general 450 the participants in our study were willing to accept a wider range of issues as valid motivators for suicide in women than in men.

The peculiar question that we asked 455 about whether or not our participants would perceive a relationship between the reason for a suicide and the method that would be selected to carry it out failed to find much of great interest. Females (more 460 than males) believed that suicide due to feelings of failure would be more likely to lead people to drown themselves and that loneliness would lead people to shoot themselves. Everyone believed that when 465 someone died by suicide because of money problems or physical illness that women would be more likely to drown themselves than men, and that for money problems and romantic problems men would be 470 more likely to hang themselves than women. However, these beliefs seemed to be by-products of other more basic beliefs about the relationship between gender and causes and methods of suicide rather than 475 distinctly different clusters of cognitions about suicide.

Our study has undeniable limitations. First of all, our research depends entirely upon self-report measures, and it is thus 480 susceptible to all of the problems inherent to this methodology. Also, the relatively small size of our sample limits the power of our statistical tests, making it difficult to reject null hypotheses. On the other 485 hand, this implies that any significant differences that occur in spite of the small $\mathrm{N}$ probably reflect fairly strong effects. Finally, we must of necessity be cautious in generalizing the results from our small, 490 primarily American college student sample 
to people of other ages and cultural backgrounds. Accepting the aforementioned limitations, we believe that our data

495 still tell us something of value about the suicide-relevant belief systems of American college students, a group that is at high risk of suicide compared to other segments of the American population (Anderson, 500 2002; Cantor, 2000; Rudd, 1989).

The major contribution of the study lies in what it adds to what we know about the expectations that college-aged people have about how suicide plays out differ-

505 ently for women and men. It appears that they are predisposed to expect women to become suicidal over relationship issues and for men to worry more about achievement, and that if suicides are carried out in

510 these situations they also expect methods of suicide that will be predictably different for men and women. Furthermore, it appears that most individuals who become aware of suicidal ideation on the part of

515 someone else will be more sympathetic to those suffering from debilitating physical and psychological problems than they will be to someone who is distraught over what are thought to be less serious issues.

520 Whether this greater sympathy translates into more proactive attempts to intervene in the potential suicide is outside of the scope of our data.

Based upon our findings, we are con-

525 cerned that potential helpers may not take threats of suicide seriously if it does not conform to their expectations, and therefore fail to do anything to prevent a tragedy. For example, a male who threatens

530 to drown himself because of a failed love affair may not be taken as seriously as a male who threatens to shoot himself after losing a job, and this may have potentially fatal consequences. Future research in this

535 area must continue to tease out the beliefs that potential helpers have about how suicide plays out, and further determine how these beliefs are related to the likelihood of intervening before it is too late.

\section{AUTHOR NOTE}

Francis T. McAndrew and Andrew J. Garrison, Department of Psychology, Knox College, Galesburg, IL, USA.

Correspondence regarding this article should be addressed to Francis T. McAndrew, 545 Department of Psychology, Knox College, Galesburg, IL, 61401, USA. E-mail: fmcandre@knox.edu

\section{REFERENCES}

Anderson, R. (2002). Deaths: Leading causes for 2000. 550 National Vital Statistics Reports. Vol. 50(16). Hyattsville, MD: National Center for Health Statistics.

Andrews, P. W. (2006). Parent-offspring conflict and cost-benefit analysis in adolescent suicidal 555 behavior. Human Nature, 17, 190-211.

Barnes, R. (1985). Women and self-injury. International Journal of Women's Studies, 5, 465-474.

Canetto, S. S. (1992-1993). She died for love and he for glory: Gender myths of suicidal behavior. 560 Omega-Journal of Death and Dying, 26, 1-17.

Canetto, S. S. (1997a). Gender and suicidal behavior: Theories and evidence. In R. W. Maris, M. M. Silverman, \& S. S. Canetto (Eds.), Review of suicidology (pp. 138-167). New York: Guilford. 565

Canetto, S. S. (1997b). Meaning of gender and suicidal behavior during adolescence, Suicide and Life-Threatening Behavior, 27, 339-351.

Canetto, S. S. \& Lester, D. (2002). Love and achievement motives in women's and men's suicide notes. 570 Journal of Psychology, 136, 573-576.

Cantor, C. H. (2000). Suicide in the western world. In K. Hawton \& K. Van Heeringen (Eds.), The international bandbook of suicide and attempted suicide, (pp. 9-26). New York: John Wiley \& Sons.

Chotai, J., Renberg, E., \& Jacobsson, L. (2002). Method of suicide in relation to some sociodemographic variables in Northern Sweden. Archives of Suicide Research, 6, 111-122.

Dahlen, E. R. \& Canetto, S. S. (2002). The role of 580 gender and suicide precipitant in attitudes toward nonfatal suicide behavior. Death Studies, 26, 99-116.

Deluty, R. H. (1988-1989). Factors affecting the acceptability of suicide. Omeg-Journal of Death 585 and Dying, 19, 315-326. 


\section{F. McAndrew and A. Garrison}

Garrison, C., McKeown, R., Valois, R., et al. (1993). Aggression, substance use, and suicidal behaviors in high school students. American Journal of Public Health, 83, 179-184.

Glasser-Frei, H. (2003). Characteristics of child suicide: Gender differences between five and nine year olds. Dissertation Abstracts International: Section B: The Sciences \& Engineering, 64(1-B), 418.

595 Gmitrowicz, A., Szymczak, W., Kropiwnicki, P., et al. (2003). Gender influence in suicidal behavior of Polish adolescents. European Child \&Adolescent Psychiatry, 12, 205-213.

Gould, M. S., Greenberg, T., Velting, D. M., et al. 600 (2003). Youth suicide risk and preventive inerventions: A review of the past 10 years. Journal of the American Academy of Child and Adolescent Psychiatry, 42, 386-405.

Hawton, K. (2000). Sex and suicide: Gender differ605 ences in suicidal behavior. British Journal of Psychiatry, 177, 484-485.

Hendin, H. (1995). Suicide in America: New and expanded edition. New York: W.W. Norton \& Company.

610 Hjelmeland, H., Knizek, B. L., \& Nordvik, H. (2002). The communicative aspect of nonfatal suicidal behavior-are there gender differences?. Crisis: The Journal of Crisis Intervention and Suicide Prevention, 23, 144-155.

615 Jack, R. (1992). Women and attempted suicide. Hillsdale, NJ: Erlbaum.

Kessler, R. C. \& McRae, J. A., Jr. (1983). Trends in the relationship between sex and attempted suicide. Journal of Health and Social Behavior, 24, 98-110.

620 Lewinsohn, P., Rohde, P., \& Seeley, J. (1996). Adolescent suicidal ideation and attempts: Prevalence, risk factors, and clinical implications. Clinical Psychology Science Practice, 3, 25-36.

Limbacher, M. \& Domino, G. (1985-1986). Atti-

625 tudes toward suicide among attempters, contemplators, and nonattempters. Omega-Journal of death and Dying, 16, 325-334.

Linehan, M. M. (1973). Suicide and attempted suicide: Study of perceived sex differences. Perceptual 630 and Motor Skills, 37, 31-34.

Marks, A. (1988-1989). Structural parameters of sex, race, age, and education and their influence on attitudes toward suicide. Omega-Journal of Death and Dying, 19, 327-336.

Mishara, B. L. (1982). College students' experiences 635 with suicide and reactions to suicidal verbalizations: A model for prevention. Journal of Community Psychology, 10, 142-150.

Mueller, M. A. \& Waas, G. A. (2002). College students' perceptions of suicide: The role of empathy 640 on attitudes, evaluation, and responsiveness. Death Studies, 26, 325-341.

Pirkola, S., Isometsa, E., \& Lohngvist, J. (2003). Do means matter? Differences in characteristics of Finnish suicide completers using different meth- 645 ods. Journal of Nervous \& Mental Disease, 191, 745-750.

Pokorny, A. D. (1965). On suicide and other forms of deviant behavior/human violence: A comparison of homicide, aggravated assault, suicide, and 650 attempted suicide. Journal of Criminal Law, Criminology, and Police Science, 56, 488-497.

Rudd, M. D. (1989). The prevalence of suicidal ideation among college students. Suicide and Life-Threatening Behavior, 19, 173-183.

Schneidman, E. (1985). Definition of suicide. New York: John Wiley \& Sons.

Spirito, A., Valeri, S., Boergers, J., et al. (2003). Predictors of continued suicidal behavior in adolescents following a suicide attempt. Journal of 660 Clinical Child and Adolescent Psychology, 32, 284-289.

Stillion, J. M. \& Stillion, B. D. (1998-1999). Attitudes toward suicide: Past, present, and future. OmegaJournal of Death and Dying, 38, 77-97.

Wagner, B. M. (1997). Family risk factors for child 665 and adolescent suicidal behavior. Psychological Bulletin, 121, 246-298.

Wagner, B. M., Aiken, C., Mullaley, P. M. et al., (2000). Parents' reactions to adolescents' suicide attempts. Journal of the American Academy of Child 670 and Adolescent Psychiatry, 39, 429-436.

White, H. \& Stillion, J. M. (1988). Sex differences in attitudes toward suicide: Do males stigmatize males?. Psychology of Women Quarterly, 12, 357-366.

Wilson, M. (1981). Suicidal behavior: Toward an 675 explanation of differences in female and male rates. Suicide and Life-Threatening Behavior, 11, 131-140. 